\title{
First study on telomerization of chitosan and guar hemicellulose with butadiene: Influence of reaction parameters on the substitution degree of the biopolymers
}

Wissam Zahreddine ${ }^{\mathrm{a}, \mathrm{b}}$, Iyad Karaméb ${ }^{\text {, Catherine Pinel }}{ }^{\mathrm{a}}$, Laurent Djakovitch ${ }^{\mathrm{a}}$, Franck Rataboul ${ }^{\mathrm{a}, *}$

a Université de Lyon, Université Lyon 1, CNRS, UMR 5256, IRCELYON, 2 Avenue Albert Einstein, F-69626 Villeurbanne, France

E-mail: franck.rataboul@ircelyon.univ-lyon1.fr

${ }^{b}$ Laboratoire de Catalyse Organométallique et Chimie de Coordination, Département de Chimie, Faculté des Sciences, Lebanese University, Rafic Hariri Campus, Hadath, Lebanon

\begin{abstract}
The direct functionalization of biopolymers is an important route towards the formation of new biosourced materials. This work describes for the first time the modification of two largely available biopolymers, chitosan and a guar hemicellulose, using the Pd-catalyzed telomerization reaction with butadiene. The reactions with butadiene formed new materials by grafting a long hydrocarbon chain at the surface of the biopolymers. These new biobased compounds were structurally characterized using ${ }^{1} \mathrm{H}$ and ${ }^{13} \mathrm{C}$ NMR spectroscopy. The telomerization was possible in green media like water or aqueous iso-propanol using water soluble catalytic systems. The study shows the possibility of adjusting the substitution degree (DS) by combining the effect of some reaction parameters and catalyst composition. For chitosan, it was possible to get DS from 0.03 to 0.60 , while for guar hemicellulose a tighter range was obtained with DS between 0.025-0.3. Wettability experiments and contact angle measurements indicate that the transformation induced new hydrophobic-hydrophilic balance within the materials of highest DS that can find potential applications for example in the field of biosourced amphiphilic materials.
\end{abstract}

\section{Keywords}

Chitosan; Hemicellulose; Palladium catalysis; Butadiene telomerization; Bioresources 


\section{Introduction}

The telomerization reaction is an efficient method to functionalize molecules.[1-3] It involves the dimerization of a 1,3-diene (usually butadiene or isoprene) with the concomitant addition of a nucleophile (mainly alcohols or amines) leading to compounds having a octa-2,7-diene chain.

Telomerization is catalyzed by phosphine or $\mathrm{N}$-heterocyclic carbene palladium complexes and is of $100 \%$ atom economy, considered therefore as a sustainable reaction. A massive amount of literature exists concerning the transformation of simple nucleophiles, however there are limited examples on the reactivity of multi-functionalized reactants. Among them, polyols available from biomass are of potential interest for the formation of biobased amphiphilic materials which can be used as non ionic surfactants or emulsifiers after partial alkylation displaying desirable properties of dermatological safety, biodegradability, wettability among others.[4] It is has been proposed for example that for light polyols (e.g. glycols, glycerol) mono telomerization is preferred for introduction of surfactant properties through adequate critical micelle concentrations, for a use as detergents or emulsifiers.[5] Concerning higher polyols, octadienyl pentosides showed interfacial properties for surfactant applications.[6] Telomerization of such biosourced compounds has been scarcely investigated, mainly with monosaccharides.[5] Considering biosourced polymers, the telomerization of lignin (polymer presenting phenolic units) with butadiene was described only very recently, $[7,8]$ and our group reported some years ago the telomerization of starch, a polysaccharide, with butadiene. $[9,10]$ In order to extent this reaction to other widely available biosourced polymers, we are currently studying the catalytic reactivity of chitosan and hemicelluloses (Figure 1).

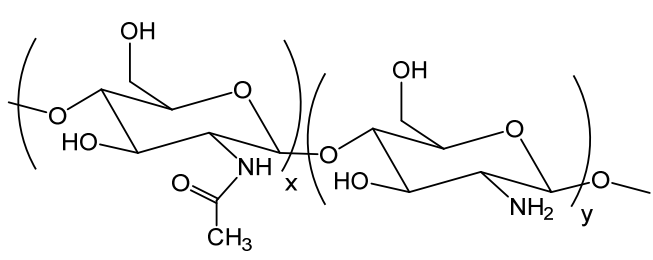

Chitosan: partly deacetylated chitin, $y=82 \%$

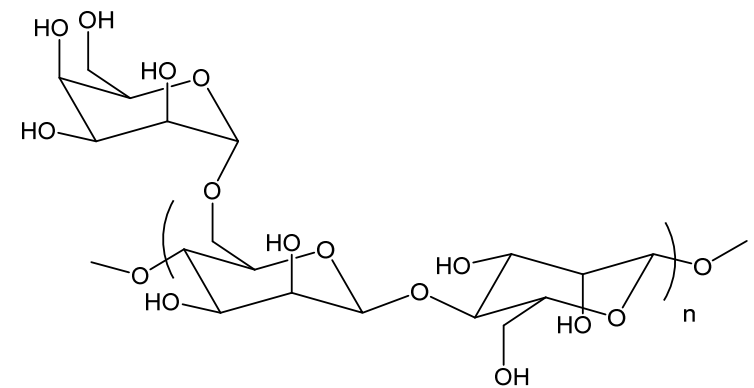

Guar hemicellulose

Fig. 1. Representation of chitosan with an acetyl glucosamine unit linked to a glucosamine unit; and of guar hemicellulose composed of mannose units with a branched galactose unit.

For industrial applications involving chemically modified polysaccharides, starch and cellulose are preferred reactants.[11, 12] Besides, hemicelluloses are polysaccharides (predominantly obtained as wastes from the paper industry) with no chemical valorization. Nevertheless chemical modification of hemicelluloses is possible and examples of esterification and cationisation have been reported forming 
new materials of specific properties.[13-19] Chitosan is a biopolymer based on glucosamine units and is directly available by partial deacetylation of chitin, obtained from arthropods or insects skeletons, giving the second most available biopolymer after cellulose. Due to the presence of a free amine function, chitosan has been used extensively as such or after chemical modification as materials for the biomedical, separation and catalysis fields.[20-25] Although catalyzed telomerization of these two bioresources can be clearly a straightforward way of valorization, this reaction has to the best of our knowledge never been reported. We describe here our first results on the telomerization of chitosan and hemicellulose, which possible mechanism is presented in Scheme 1 based on the adopted general mechanism[1]. Our objective was to study as much as possible a sustainable valorization and for that we privileged aqueous solvents associated with water soluble Pd complexes as catalytic system. The influence of various parameters has been studied and specific points allowing the formation of materials with different substitution degrees are discussed in details.

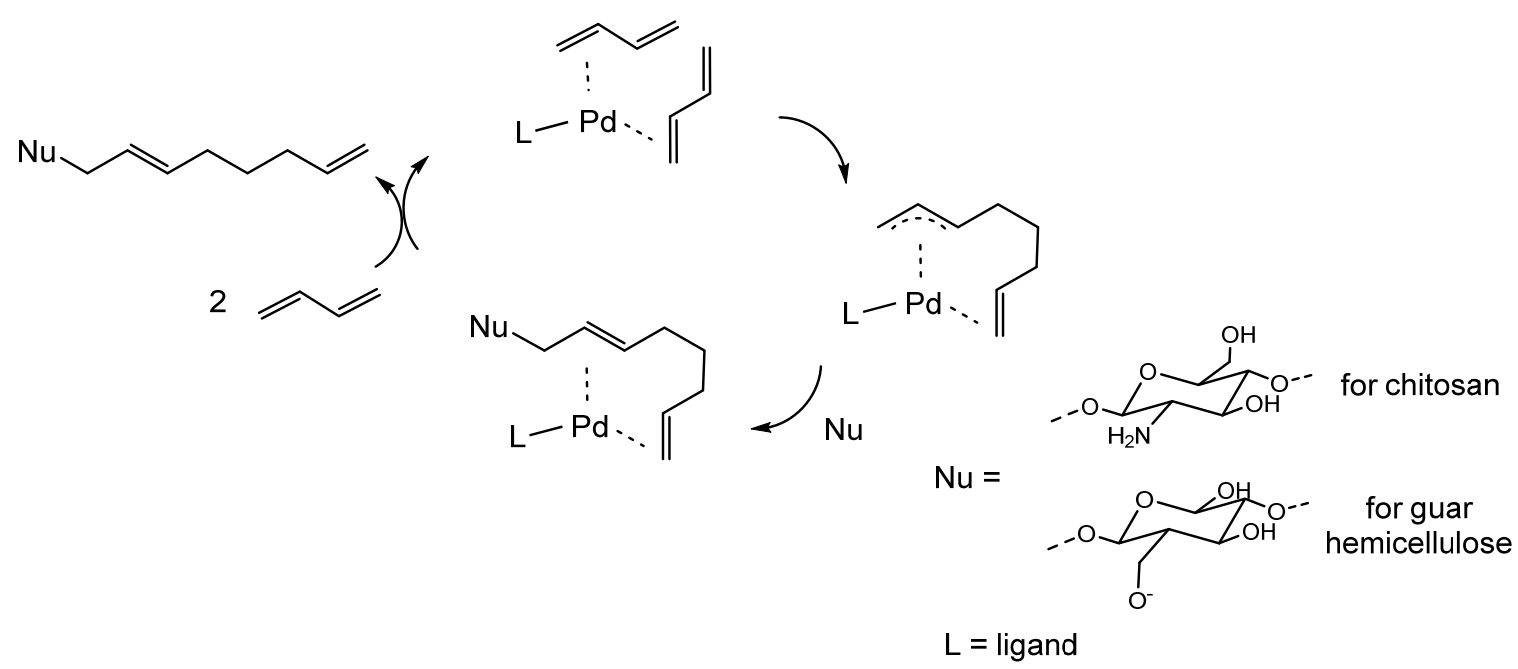

Scheme 1. Main steps of the mechanism of telomerization of butadiene.

\section{Experimental}

\subsection{Chemicals}

All reagents were used as received. Chitosan of medium molecular weight (average unit $M=168.5$ g. $\mathrm{mol}^{-1}$ ) is a slightly fibrous powder of very pale yellow color. It has an estimated deacetylation degree of $82 \%$ (see Supplementary information for details). Guar hemicellulose (average unit $\mathrm{M}=162 \mathrm{~g} \cdot \mathrm{mol}^{-}$ $\left.{ }^{1}\right)$ is a fine powder of same color. Both reactants along with CTAB and iso-propanol were obtained from Sigma. Butadiene was provided by Air Liquide in a N26 cylinder directly connected to the reactor via a dropping funnel. Pd precursors and TPPTS ligand were obtained from Strem.

\subsection{Catalyzed telomerization procedure}


Detailed concentrations of reagents are indicated thorough the text for each experiment (see corresponding Figures in the Results and discussion section). Reactions were performed in a $100 \mathrm{~mL}$ batch autoclave equipped with a mechanical stirring and plugged thermocouple. After introduction of the biopolymer, the base (if any), the surfactant (if any), the palladium precursor, the ligand and the solvent, the autoclave was purged with argon and cooled to $-30{ }^{\circ} \mathrm{C}$ using liquid nitrogen. A measuring dropping funnel equipped with a cooling mantel connected to the autoclave allowed the controlled introduction of an accurate volume of liquid butadiene directly from the cylinder. The reaction mixture was heated $\left(5^{\circ} \mathrm{C} \cdot \mathrm{min}^{-1}\right)$ to the desired temperature under $1000 \mathrm{rpm}$ stirring and left for the desired time. Then, the reactor was cooled to room temperature using an ice bath, and unreacted butadiene was evacuated. The solid product was collected by centrifugation, washed with water ( 2 times), filtered and dried overnight at room temperature.

Telomerized chitosan was recovered as solid of similar aspect to initial chitosan. Telomerized guar hemicellulose was recovered as non powdered solid, with a light green coloration, that was grounded to powder by manual milling for subsequent analysis. For both transformations, the ratio of recovered solid was in the range of $70-90 \%( \pm 5 \%)$. Detailed calculations are given in Supplementary information. Elemental analysis $(\mathrm{C}, \mathrm{H}, \mathrm{N})$ of samples of various substitution degrees are given for chitosan in Supplementary information. These products contained respectively 1 and $2.5 \mathrm{ppm}$ of $\mathrm{Pd}$. This corresponds to $65 \%$ and $78 \%$ of initial Pd introduced in the reaction media.

\subsection{Product analysis}

Substitution degree (DS) was defined as the number of substituted functions per sugar unit. For chitosan the sugar unit corresponds to the glucosamine moiety, DS max is 0.82 if we consider only a single telomerization at the $\mathrm{NH}_{2}$ function (Fig. 1). For guar hemicellulose maximum DS is 3 if we consider the average $\mathrm{OH}$ functions of the 2 mannose-1 galactose sequence (Fig. 1).

Butadiene efficiency for product formation was calculated as the ratio of reacted butadiene for biopolymer telomerization to introduced butadiene. Reacted butadiene for biopolymer telomerization was determined directly from the DS taking into consideration that 2 molecules of butadiene were involved for 1 substitution. Note that in our operating conditions, it appeared difficult to determine whether butadiene not involved in biopolymer telomerization gave side-products (e.g. dimerization, hydrodimerization, formation of 4-vinyl-cyclohexene, iso-propanol telomerization) or was let unreacted. Also the presence of possible side-products was not determined since the study focused on the formation of solid products.

DS were determined by ${ }^{1} \mathrm{H}$ NMR spectroscopy (Avance DSX400 Bruker spectrometer) with a variation of \pm 0.01 unit. See Results and discussion section for details.

All samples were dissolved under heating in $6 \% \mathrm{vol} \mathrm{DCl}$ in $\mathrm{D}_{2} \mathrm{O}\left(0.85 \mathrm{~mL}, 200{ }^{\circ} \mathrm{C}, 10 \mathrm{~min}\right)$ for chitosan,

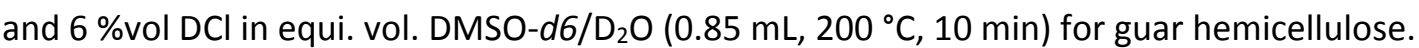


Telomerized chitosan (Fig. 2): ${ }^{1} \mathrm{H}$ NMR (400 MHz, $80{ }^{\circ} \mathrm{C}$, D1 = $4 \mathrm{~s}, 128$ scans): $\delta$ ppm: 1.83 (m, $\mathrm{H}_{\mathrm{e}}, 1.74$ H), $2.43\left(\mathrm{~m}, \mathrm{H}_{\mathrm{d}}, 1.00 \mathrm{H}\right), 2.45\left(\mathrm{~s}, \mathrm{CH}_{3} \mathrm{CO}, 2.68 \mathrm{H}\right), 2.51\left(\mathrm{~m}, \mathrm{H}_{\mathrm{f}}, 1.24 \mathrm{H}\right), 3.48(\mathrm{~s}, \mathrm{NH}, 0.42 \mathrm{H}), 3.60\left(\mathrm{t}, \mathrm{H}_{2}\right.$, $\left.{ }^{3} J_{H-H} 9.1 \mathrm{~Hz}, \mathrm{CH}-\mathrm{NH}, 2.11 \mathrm{H}\right), 3.8-4.0\left(\mathrm{~m}, \mathrm{H}_{\mathrm{a}^{\prime}}, 0.99 \mathrm{H}\right), 4.01-4.38\left(\mathrm{~m}, \mathrm{H}_{3 / 6}\right.$ and $\left.\mathrm{H}_{2^{\prime}-6^{\prime}}, 12 \mathrm{H}\right), 4.44\left(\mathrm{~m}, \mathrm{H}_{\mathrm{a}}, 0.96\right.$ H), $5.30\left(\mathrm{~d}, \mathrm{H}_{1}, 3^{3} \mathrm{~J}_{H-H} 8.10 \mathrm{~Hz}, 1.75 \mathrm{H}\right), 5.41\left(\mathrm{~m}, \mathrm{H}_{\mathrm{h}}, 1.33 \mathrm{H}\right), 5.62(\mathrm{~s}, \mathrm{NH}, 0.38 \mathrm{H}), 5.96\left(\mathrm{~m}, \mathrm{H}_{\mathrm{b}}, 1.01 \mathrm{H}\right)$, 6.15-6.26 $\left(\mathrm{m}, \mathrm{H}_{\mathrm{g}}, 0.76 \mathrm{H}\right), 6.43\left(\mathrm{~m}, \mathrm{H}_{\mathrm{c}}, 0.85 \mathrm{H}\right)$. Integral of signals at 4.01-4.38 was arbitrarily fixed at 12 protons.

Telomerized guar hemicellulose (Fig. 7): ${ }^{1} \mathrm{H}$ NMR (400 MHz, $\left.25^{\circ} \mathrm{C}, \mathrm{D} 1=1 \mathrm{~s}, 128 \mathrm{scans}\right): \delta$ ppm: 0.97 (m, $\left.H_{e}, 0.15 H\right), 1.03\left(m, H_{f}, 0.17 \mathrm{H}\right), 1.87\left(m, H_{d}, 0.27 \mathrm{H}\right), 3.10-3.86\left(m, \mathrm{H}_{2 / 6}-\mathrm{H}_{2^{\prime} / 6^{\prime}}-\mathrm{H}_{2^{\prime \prime} / 6^{\prime \prime}}, 18 \mathrm{H}\right), 4.31$ (d, $\mathrm{H}_{\mathrm{G} 1 \beta}$, $\left.{ }^{3} J_{H-H} 7.8 \mathrm{~Hz}, 0.67 \mathrm{H}\right), 4.49\left(\mathrm{~m}, \mathrm{H}_{\mathrm{a}}, 0.21 \mathrm{H}\right), 4.63\left(\mathrm{~s}, \mathrm{H}_{\mathrm{M} 1 \beta}, 0.32 \mathrm{H}\right), 4.91\left(\mathrm{~s}, \mathrm{H}_{\mathrm{M} 1 \alpha}, 1.11 \mathrm{H}\right), 4.99\left(\mathrm{~d}, \mathrm{H}_{\mathrm{G} 1 \alpha},{ }^{3} J_{H-}\right.$ H $3.5 \mathrm{~Hz}, 0.6 \mathrm{H}), 7.61\left(\mathrm{~m}, \mathrm{H}_{\mathrm{h}}, 0.16 \mathrm{H}\right), 7.69-8.01\left(\mathrm{~m}, \mathrm{H}_{\mathrm{c}}+\mathrm{H}_{\mathrm{b}}+\mathrm{H}_{\mathrm{g}}, 0.23 \mathrm{H}\right)$. Integral of signals at 3.10-3.86 ppm was arbitrarily fixed at 18 protons. The presence of impurity in starting guar hemicellulose at 1.88 ppm prevents careful integration of this signal (see Insert in Fig. 7).

CP-MAS ${ }^{15} \mathrm{~N}$ solid-sate NMR was performed on a AVANCE III 500WB Bruker spectrometer, using acquisition conditions specified in Fig. S5 in Supplementary information.

ESI mass spectroscopy was performed on a Impact II QTOF Bruker spectrometer at the Centre Commun de Spectrométrie de Masse of University Lyon 1. Samples were dissolved under heating in $6 \% \mathrm{vol} \mathrm{HCl}$ in $\mathrm{H}_{2} \mathrm{O}\left(5 \mathrm{~g} \cdot \mathrm{L}^{-1}, 200^{\circ} \mathrm{C}, 10 \mathrm{~min}\right)$. Analysis of telomerized chitosan samples shows the presence of $[\mathrm{M}+\mathrm{H}]^{+}$ at $\mathrm{m} / \mathrm{z}=288.1809\left(\mathrm{C}_{14} \mathrm{H}_{26} \mathrm{NO}_{5}\right)$ corresponding to telomerized amino-glycosides moieties $\mathrm{C}_{14} \mathrm{H}_{25} \mathrm{NO}_{5}$ (Fig. S6 in Supplementary information with analysis conditions).

ATR mode infrared spectroscopy was performed on a Nicolet iS5 apparatus (Fig. S7 and S14 in Supplementary information). Spectra of telomerized biopolymers did not display much change after telomerization. In the case of guar no apparent difference was noticed. The substitution of chitosan can be more significantly (qualitatively) observed by the relative decrease of the $\mathrm{vNH}_{2}$ band intensity $\left(1560 \mathrm{~cm}^{-1}\right)$ compared to the signal in the $1250-1450 \mathrm{~cm}^{-1}$ area, especially for the highest DS.

Pd content on telomerized biopolymers was determined on a ICP-OES Activa apparatus after acidic dissolution at $350^{\circ} \mathrm{C}$.

Wettability was assessed on a GBX DIGIFROP apparatus. A $1 \mu$ l water droplet was deposited on the powdered biopolymer (supported on a glass plate) and pictures were registered using a CCD camera, after identical adsorption time for each sample.

\section{Results and discussion}

\subsection{Telomerization of chitosan}

\subsubsection{NMR analysis and substitution degree determination}


Chitosan possesses two different functions that can be substituted via telomerization: $-\mathrm{OH}$ and $-\mathrm{NH}_{2}$ (Fig. 1 and Scheme 2). For the present work, our goal was to study the possibility to substitute only the amine group leaving unreacted the hydroxyl functions. Previous studies on telomerization of ethanolamine[26] and $\mathrm{N}$-methylglucamine[27, 28] showed in the absence of a base the reactivity of the amine group only. Moreover, reports on chitosan modification indicate that $-\mathrm{NH}(\mathrm{OAc})$ function was also not reactive and modifications occur at $-\mathrm{NH}_{2}$ groups.[29] These considerations allows us to propose the structure depicted in Scheme 2 for the products that can arise from the catalytic telomerization of chitosan, in the absence of a base.

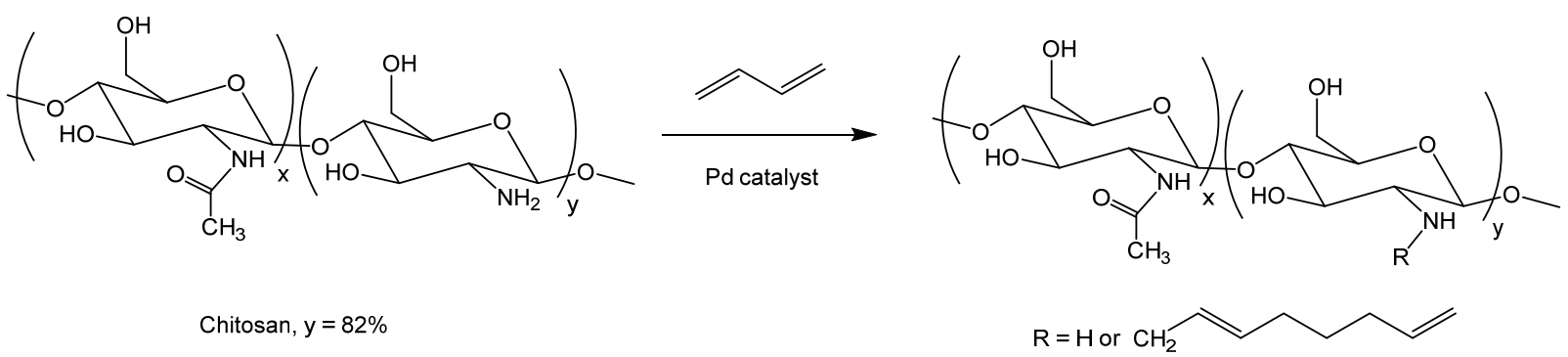

Scheme 2. Possible representation of chitosan before and after telomerization with butadiene.

Proton NMR spectroscopy was used to determine the degree of substitution of chitosan (DS, see Experimental section for details). Fig. 2 display a typical spectrum of chitosan after telomerization, and comparison can be made with spectrum of initial chitosan (Fig. S1 in Supplementary information). 


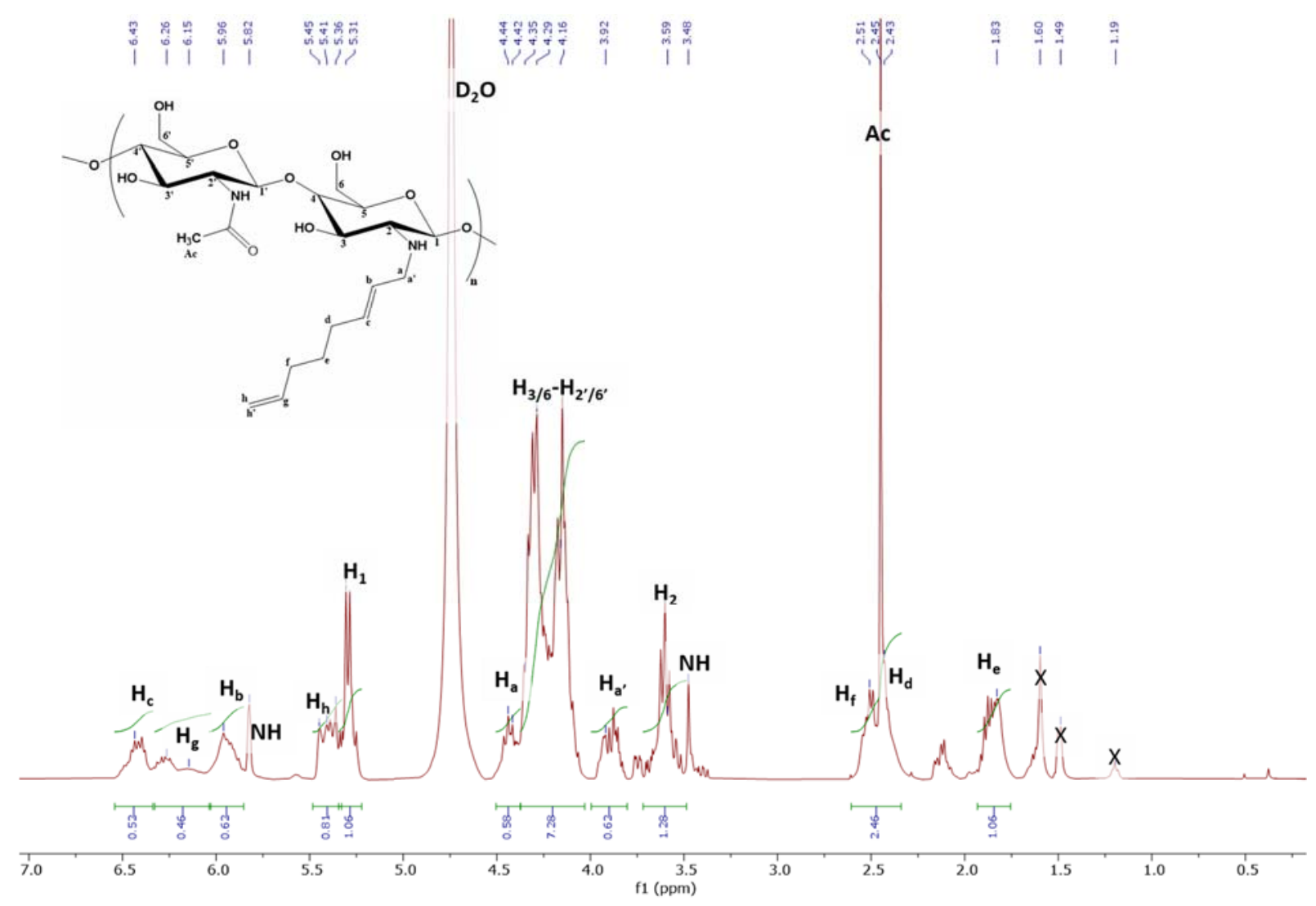

Fig. 2. ${ }^{1} \mathrm{H}$ NMR spectrum of chitosan after reaction (see Figures S2-S4 in Supplementary information for ${ }^{13} \mathrm{C}$ and HSQC spectra), DS $=0.30$.

Chitosan moiety can be easily identified by key signals: acetyl group Ac at $2.45 \mathrm{ppm}$, proton linked to the carbon adjacent to primary amine/urea moiety $\mathbf{H}_{\mathbf{2}}$ at $3.59 \mathrm{ppm}$, glucosamine unit, $\mathbf{H}_{3 / 6}-\mathbf{H}_{2^{\prime}-6^{\prime}}$ at $4.00-$ $4.39 \mathrm{ppm}$ and the anomeric proton $\mathbf{H}_{\mathbf{1}}$ at $5.29 \mathrm{ppm}$. The product of telomerization is characterized by signals belonging to introduced octadienyl chain. Particularly protons characteristic of $\mathrm{C}=\mathrm{C}$ bonds are clearly identified at $5.42\left(\mathbf{H}_{h}\right), 5.94\left(\mathbf{H}_{\mathbf{b}}\right), 6.15-6.23\left(\mathbf{H}_{\mathrm{g}}\right)$ and $6.42\left(\mathbf{H}_{\mathrm{c}}\right) \mathrm{ppm}$. The signals corresponding to the internal $\mathrm{CH}_{2}$ units of the chain can be observed at $1.84\left(\mathbf{H}_{\mathrm{e}}\right), 2.43\left(\mathbf{H}_{\mathrm{d}}\right)$ and $2.51\left(\mathbf{H}_{\mathrm{f}}\right)$ ppm. Protons of the methylene group adjacent to $\mathrm{NH}$ give two massifs at $3.92\left(\mathbf{H}_{\mathrm{a}^{\prime}}\right)$ and $4.43\left(\mathbf{H}_{\mathrm{a}}\right)$ ppm. Attribution is confirmed by HSQC experiments (Fig. S4 in Supplementary information). By analogy with the determination of the degree of deacetylation, DS was calculated using the following equation based on the integral of signals of $\mathbf{H}_{\mathbf{2}}$ and $\mathbf{H}_{\mathrm{e}}$. In this example, DS corresponds to 0.30. Alternative method based on $\mathbf{H}_{\mathbf{b}}$ proton delivers the same DS (see Supplementary information for equation).

$$
\mathrm{DS}=\frac{\frac{\int \mathbf{H}_{\mathbf{e}}}{2}}{\int \mathbf{H}_{\mathbf{2}}+\frac{\int \mathbf{H}_{\mathbf{e}}}{2}}
$$


The telomerization at the amine function was confirmed by CP-MAS ${ }^{15} \mathrm{~N}$ solid-state NMR (Figure S5 in Supplementary information). While spectrum of initial chitosan displays two signals at $98\left(\mathrm{NH}-\mathrm{CO}-\mathrm{CH}_{3}\right)$ and $0.3 \mathrm{ppm}\left(\mathrm{NH}_{2}\right),[30]$ that of telomerized chitosan shows an additional signal at $18 \mathrm{ppm}$ that was, based on available literature data, attributed to alkylated amino groups.[31, 32]

\subsubsection{Influence of reaction conditions on the substitution degree of chitosan}

This section describes the most significant effects of reaction conditions on the substitution degree. An important issue for this kind of reaction involving biopolymers is the solvent system that may allow particularly maximum interaction between the biopolymer, the catalytic species, and butadiene. We choose for the first set of experiments some conditions based from previously reported starch telomerization.[9, 10] To enhance butadiene transfer we particularly used water in the presence of cetyltrimetyl ammonium bromide (CTAB) surfactant with iso-propanol as co-solvent (not prone to significant telomerization[33, 34]). Note that in contrast to the reaction with starch, we used initially an excess of butadiene. As another difference, starch telomerization necessitated the use of $\mathrm{Na}_{2} \mathrm{SO}_{4}$ additive to maintain the granular aspect of this biopolymer. We noticed here that it was not necessary for chitosan that kept its slightly fibrous aspect even after modification. Concerning the catalytic system, TPPTS was used as water-soluble ligand associated to $\mathrm{Pd}(\mathrm{acac})_{2}$ as Pd precursor that showed good results for the telomerization of ethanolamine with isoprene.[26] In contrast to starch, chitosan is not soluble (even as a gel) in this solvent system and is partly soluble in acidic solution only (forming a viscous gel). Initial results (Fig. 3a) indicate that acid conditions limited the telomerization due to protonation of amine groups giving therefore a lower DS than in neutral medium. Interestingly the presence of a base had no impact on DS and it seems that even there only $-\mathrm{NH}_{2}$ functions have been telomerized. In these conditions a DS up to 0.27 was obtained after $20 \mathrm{~h}$ in the presence of an excess of butadiene. Therefore for the following, reactions have been performed in neutral medium using chitosan suspension in the solvent, the catalytic system being initially soluble. Since the presence of CTAB appeared necessary to get efficient transformation, the next set of experiments consisted in reducing the quantity of iso-propanol with the aim to perform the reaction in more sustainable conditions by limiting the use of additives in water (Fig. 3b). Here the advantage of using CTAB vs. isopropanol was the need of a much lower amount. 

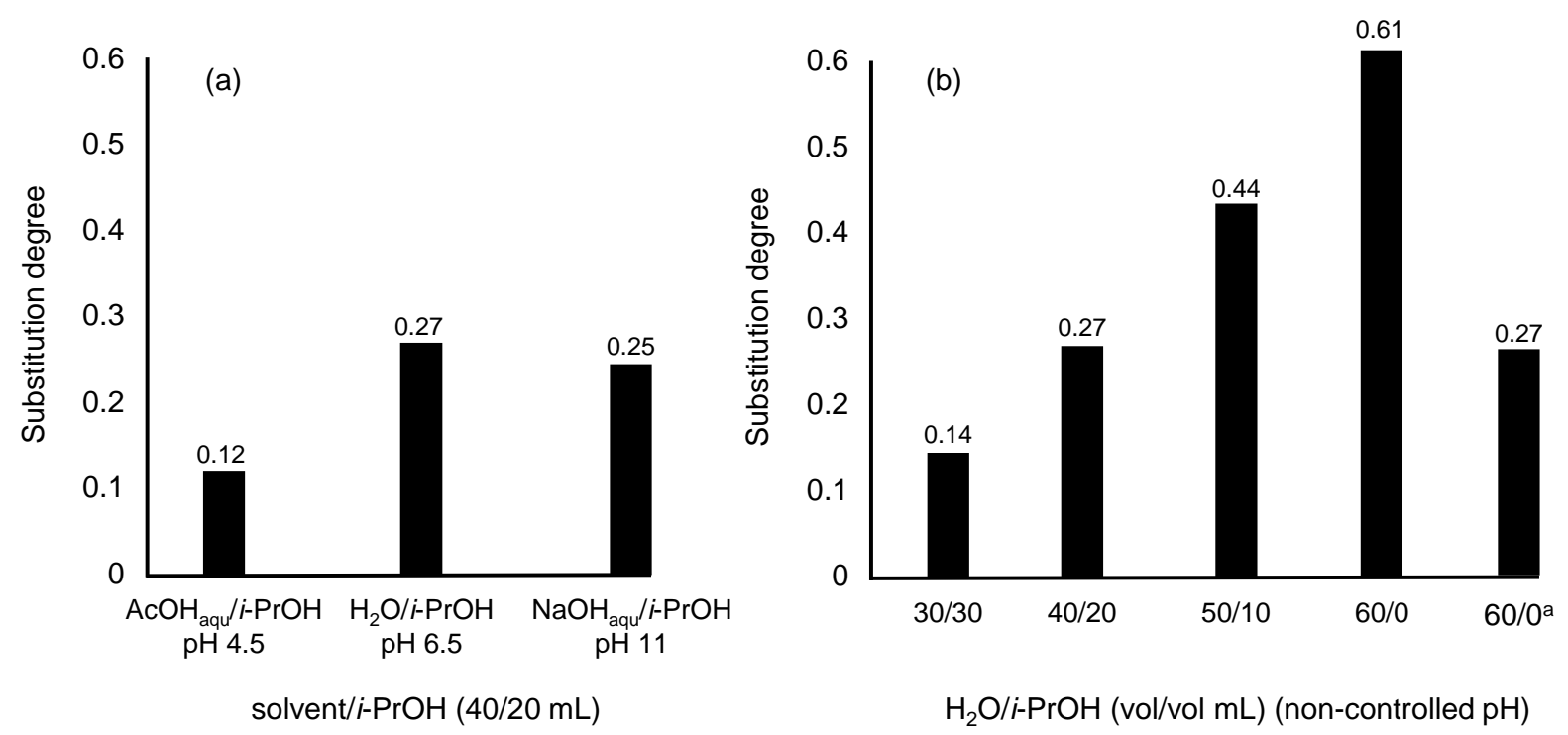

Fig. 3. Influence of solvent system for chitosan telomerization. Chitosan $1 \mathrm{~g}\left(6 \mathrm{mmol}, 4.9 \mathrm{mmol}\right.$ of $\left.\mathrm{NH}_{2}\right)$, butadiene $4 \mathrm{~mL}$ (45 mmol, 9.2 equiv./ $\mathrm{NH}_{2}$ ), Pd(acac) $4.5 \mathrm{mg}$ (Pd: $\left.0.015 \mathrm{mmol}, 250 \mu \mathrm{mol} . \mathrm{L}^{-1}, 0.25 \mathrm{~mol} \% / \mathrm{chitosan}\right)$, TPPTS $25.6 \mathrm{mg}\left(0.045 \mathrm{mmol}, 750 \mu \mathrm{mol} . \mathrm{L}^{-1}, 3\right.$ equiv./Pd), CTAB $33.3 \mathrm{mg}$ (0.091 mmol, $0.0015 \mathrm{mmol} . \mathrm{L}^{-1}, 0.002$ equiv./butadiene), solvent $60 \mathrm{~mL}, 60^{\circ} \mathrm{C}, 20 \mathrm{~h}$. ${ }^{\text {a }}$ No CTAB.

Surprisingly, decreasing the proportion of iso-propanol led to higher DS up to 0.61 in water, not far from the maximum theoretical DS attainable (0.82). Therefore the presence of iso-propanol was detrimental if one would like to get high DS. This was certainly because chitosan telomerization was more efficient taking place at the water-butadiene interface. In these conditions the role of the CTAB surfactant was favored in the absence of iso-propanol allowing the formation of an oil-in-water emulsion maximizing the contact with the water-soluble catalytic system (Fig. 4). This was confirmed by the much lower DS (0.27) obtained in the absence of CTAB in water.

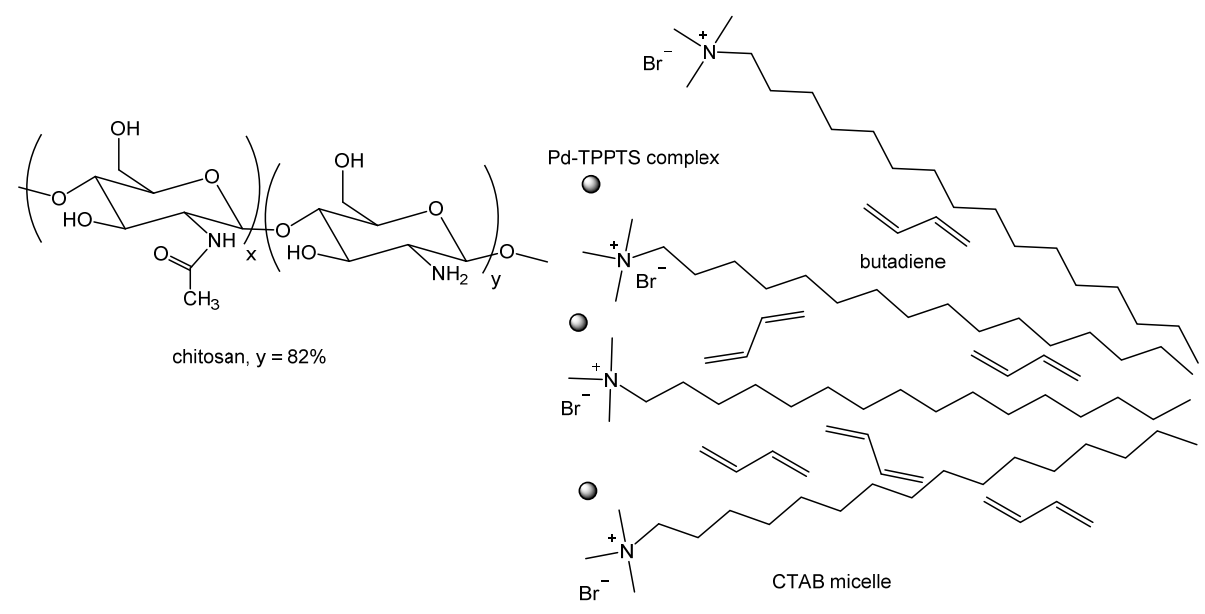

Fig. 4. Schematic representation of possible interaction of chitosan with butadiene and the catalytic species in water in the presence of CTAB.

Then, some conditions of reaction in water were varied to determine any influence on the telomerization. Notably, as expected decreasing the reaction time and the butadiene amount (Fig. 5) 
decreased the DS however not lower than 0.20 (in water). In fact if one would like to form products with much lower DS, the best way was to perform the reaction as initially investigated in the presence of iso-propanol which has shown to limit the catalyst efficiency. Here varying for example the temperature (Fig. S8 in Supplementary information), the reaction time and the butadiene quantity it was possible to get DS close or lower than 0.10 (Fig. 5). A temperature of $60^{\circ} \mathrm{C}$ appeared to be sufficient for highest substitutions. Note that in water, at constant CTAB concentration, lowering the amount of butadiene compared to the results described above (i.e. 7 vs. 9.2 equiv./ $\mathrm{NH}_{2}$ ) resulted in a much higher DS. This was explained by the formation, above a certain butadiene amount, of a separated organic liquid phase possibly limiting the efficiency of the catalyst present in the water phase. This phenomenon appearing in water was confirmed by the fact that butadiene efficiency for product formation (see Experimental section for definition and determination) was not constant and depended on the introduced amount: in water, the higher butadiene content, the lower butadiene efficiency, butadiene being probably involved in side-reactions (dimerization, water telomerization...). At lower butadiene concentration, the reaction became less efficient indicating that a certain amount is nevertheless necessary to enhance mass transfer. In the presence of iso-propanol, the phenomena are different due to the ability of iso-propanol to homogenize the liquid phases giving a close butadiene efficiency whatever the initial charge. Here the issue of mass transfer butadiene was less significant.
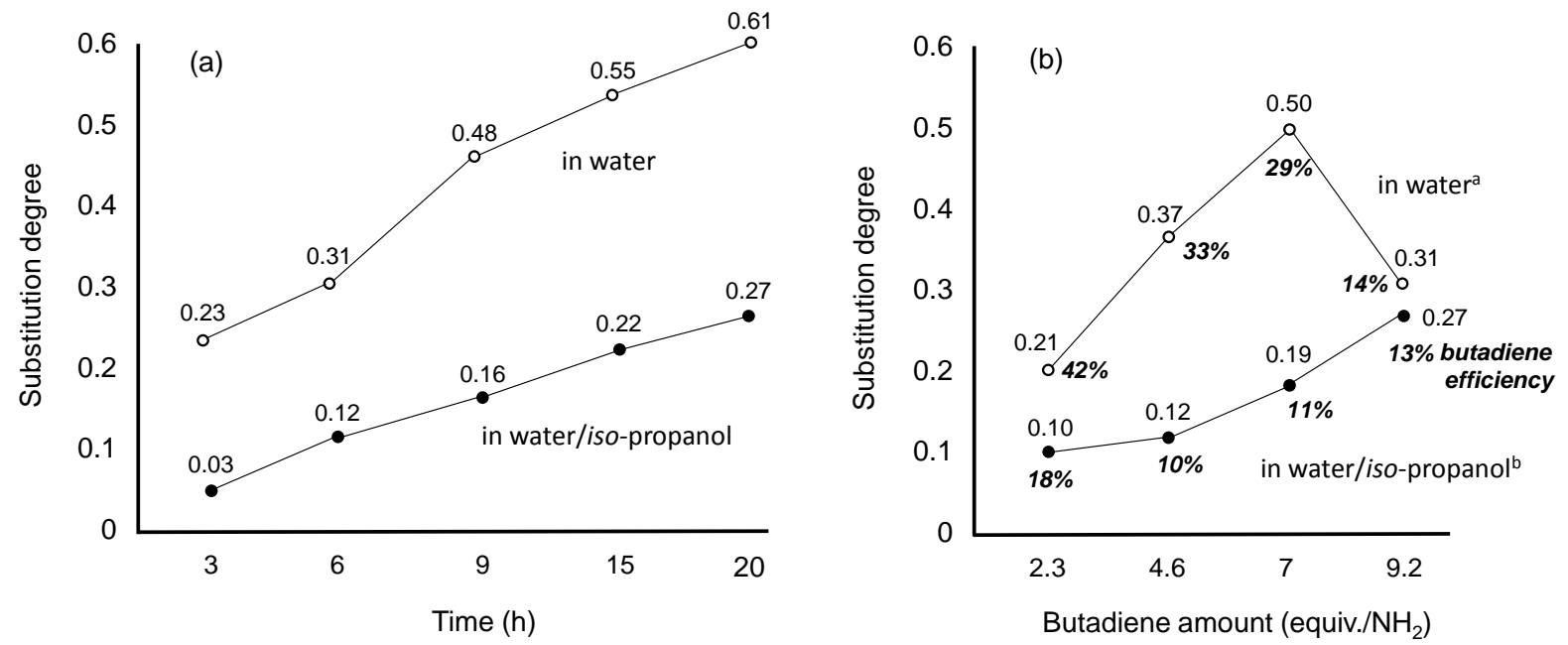

Fig. 5. Influence of time and butadiene equivalents for chitosan telomerization depending of solvent system. (a) Chitosan $1 \mathrm{~g} \mathrm{(6} \mathrm{mmol,} 4.9 \mathrm{mmol}$ of $\mathrm{NH}_{2}$ ), butadiene $4 \mathrm{~mL}\left(45 \mathrm{mmol}, 9.2\right.$ equiv./ $\mathrm{NH}_{2}$ ), Pd(acac) $4.5 \mathrm{mg}$ (Pd: 0.015 $\mathrm{mmol}, 250 \mu \mathrm{mol} . \mathrm{L}^{-1}, 0.25 \mathrm{~mol} \% /$ chitosan), TPPTS $25.6 \mathrm{mg}$ (0.045 mmol, $750 \mu \mathrm{mol} . \mathrm{L}^{-1}, 3$ equiv./Pd), CTAB $33.3 \mathrm{mg}$ (0.091 mmol, 0.0015 mmol. $\mathrm{L}^{-1}, 0.002$ equiv./butadiene), solvent $60 \mathrm{~mL} \mathrm{H} 2 \mathrm{O}$ or $40 / 20 \mathrm{~mL} \mathrm{H}_{2} \mathrm{O} / \mathrm{i}-\mathrm{PrOH}, 6{ }^{\circ} \mathrm{C}, 3-20$ h. (b) See (a) except butadiene (2.3-9.2 equiv./ $\left.\mathrm{NH}_{2}\right),{ }^{\mathrm{a}} 6 \mathrm{~h},{ }^{\mathrm{b}} 20 \mathrm{~h}$.

Finally, the influence of catalyst composition in water was investigated. An amount of 2 to 3 equivalents of TPPTS ligands per Pd was necessary to maintain a high reactivity (Fig. S9 in 
Supplementary information). Besides, the content of $\mathrm{Pd}$ and the nature of Pd precursor were studied after shorter reaction times ( 6 and $3 \mathrm{~h}$ ). As expected the DS increased with the Pd content but not linearly and DS had a tendency to reach a plateau (Fig. 6a). This feature is common in Pd-catalysis and is due to the agglomeration of $\mathrm{Pd}$ species rending part of the Pd inactive on the form of black $\mathrm{Pd}$ particles as visually observed here.[35] Besides, over various Pd precursors [ $\mathrm{Pd}(\mathrm{allyl}) \mathrm{Cl}]_{2}$ was the most efficient giving higher DS (Fig. 6b) after $3 \mathrm{~h}$. This was due to the ability of this precursor to coordinate more rapidly butadiene molecules, favoring the formation of the intermediate Pd-allyl complex,[36] but this influence was limited after much longer reaction time, giving a DS similar to that obtained with $\mathrm{Pd}(\mathrm{acac})_{2}$ after $20 \mathrm{~h}$ of reaction.
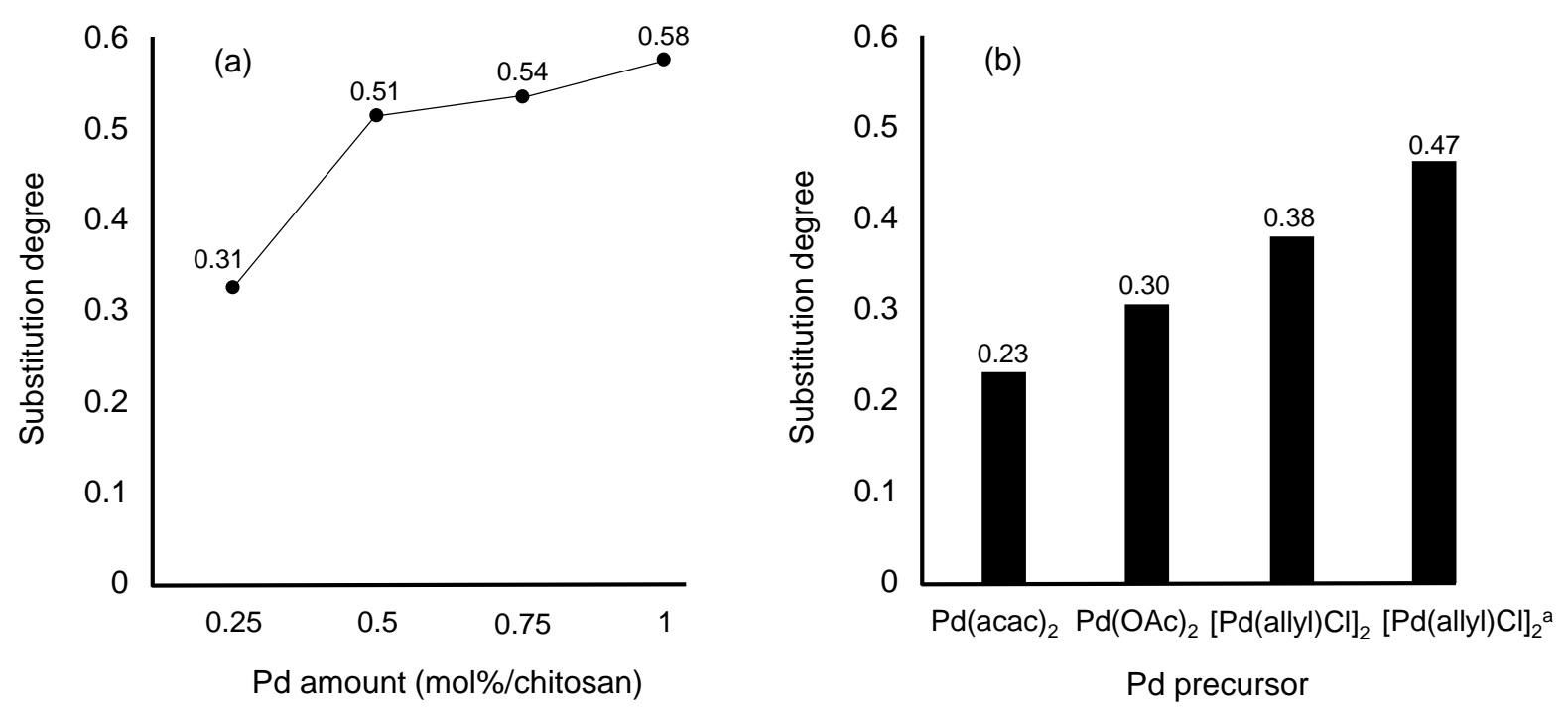

Fig. 6. Influence catalytic system for chitosan telomerization. (a) Chitosan $1 \mathrm{~g}\left(6 \mathrm{mmol}, 4.9 \mathrm{mmol}\right.$ of $\left.\mathrm{NH}_{2}\right)$,

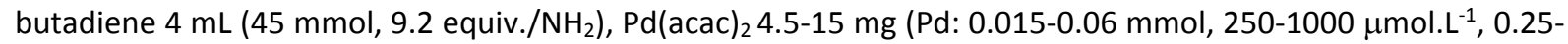

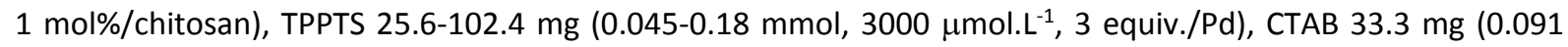
$\mathrm{mmol}, 0.0015 \mathrm{mmol} . \mathrm{L}^{-1}, 0.002$ equiv./butadiene), water $60 \mathrm{~mL}, 60^{\circ} \mathrm{C}, 6 \mathrm{~h}$. (b) See (a) except Pd(acac) $24.5 \mathrm{mg}$,

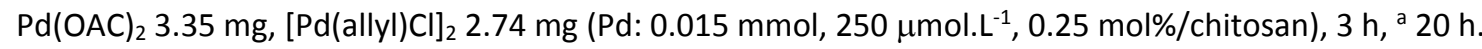

As conclusion, this study on the catalyzed telomerization of chitosan with butadiene showed the possibility of forming modified chitosan with substitution degree in a large range of $0.03-0.60$ by adjusting some reaction parameters. On the one hand, due to the relative high reactivity of amine functions of chitosan it was possible to get DS not far from the maximum attainable. On the other hand, low DS were also possible, close to those obtained previously for starch telomerization. $[9,10]$

\subsection{Telomerization of guar hemicellulose}

\subsubsection{NMR analysis and substitution degree determination}

The hemicellulose we studied for telomerization was originated from guar gum. The repeated sequence of this polysaccharide is composed of 2 linear mannose units with a branched galactose unit (Fig. 1 and Scheme 3). Note that in contrast to chitosan for which the amino groups are prone to be 
preferentially substituted, here not all of these hydroxyl groups are equally reactive (e.g. primary vs. secondary) and even with deep NMR analysis (see below), it was not possible at this stage to determine a specific regioselectivity.

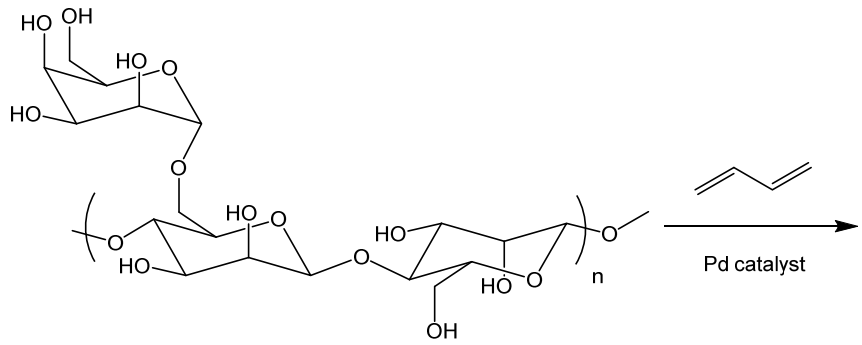

Guar hemicellulose
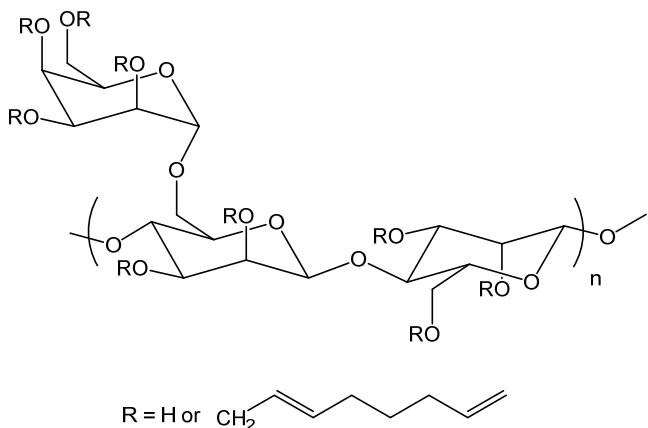

Scheme 3. Possible representation of guar hemicellulose, before and after telomerization with butadiene.

NMR spectra of initial guar hemicellulose are provided in Supplementary information (Fig. S10-S12). ${ }^{1} \mathrm{H}$ NMR spectrum shows two distinct areas, from 2.98 to $3.87 \mathrm{ppm}$ attributed to protons from mannose $(M)$ and galactose $(G)$ units except peaks attributed to anomeric protons that are found between 4.21 and $5.03 \mathrm{ppm}$. In more details, regarding the signals characteristic of the anomeric protons, we could observe signals for the $\alpha$ and $\beta$ forms of mannose units at, respectively 4.90 and $4.62 \mathrm{ppm}$ from which we calculated the ratio $\mathrm{M}_{\alpha} / \mathrm{M}_{\beta}=78 / 22$; and signals corresponding to the $\alpha$ and $\beta$ forms of galactose units at respectively $4.98(\mathrm{~d}, J=2.7 \mathrm{~Hz})$ and $4.30(\mathrm{~d}, J=7.7 \mathrm{~Hz})$ ppm allowed to calculate a ratio $G_{\alpha} / G_{\beta}=36 / 64$.[18] From this spectrum we also calculated the ratio $M / G=1.8$ (close to the theoretical of 2 ).

As for chitosan, ${ }^{1} \mathrm{H}$ NMR spectroscopy was used to determine the degree of substitution of guar hemicellulose. Fig. 7 displays a typical spectrum of guar hemicellulose after telomerization, and comparison can be made with spectrum in Fig. S10. In addition to the different signals of the initial guar hemicellulose, signals corresponding to the introduced octadienyl chain are well identified. Internal $\mathrm{CH}_{2}$ moieties of the carbon chain provide signals at $0.97,1.03$ and $1.87 \mathrm{ppm}$ corresponding, respectively to $\mathbf{H}_{\mathrm{e}}, \mathbf{H}_{\mathrm{f}}$ and $\mathbf{H}_{\mathrm{d}}$. Moiety $\mathrm{OCH}_{2}-\mathrm{CH}=$ gives a massif at $4.49 \mathrm{ppm}\left(\mathbf{H}_{\mathrm{a}}\right)$. Protons characteristic of $\mathrm{C}=\mathrm{C}$ bonds are observed at $7.58\left(\mathbf{H}_{\mathrm{h}}\right), 7.81(\mathbf{H c}), 7.84\left(\mathbf{H}_{\mathrm{b}}\right)$ and $7.89\left(\mathbf{H}_{\mathrm{g}}\right)$ ppm. DS was calculated using the following equation based on integral of signals of $\left(\mathbf{H}_{\mathrm{e}}+\mathbf{H}_{\mathrm{f}}\right)$ and $\mathbf{H}_{\mathrm{M} 1 \beta}$ protons. In this example, DS corresponds to 0.20 . Note that for some experiments, due to overlapping signals, an alternative equation can be used giving the same result (see Supporting information). 


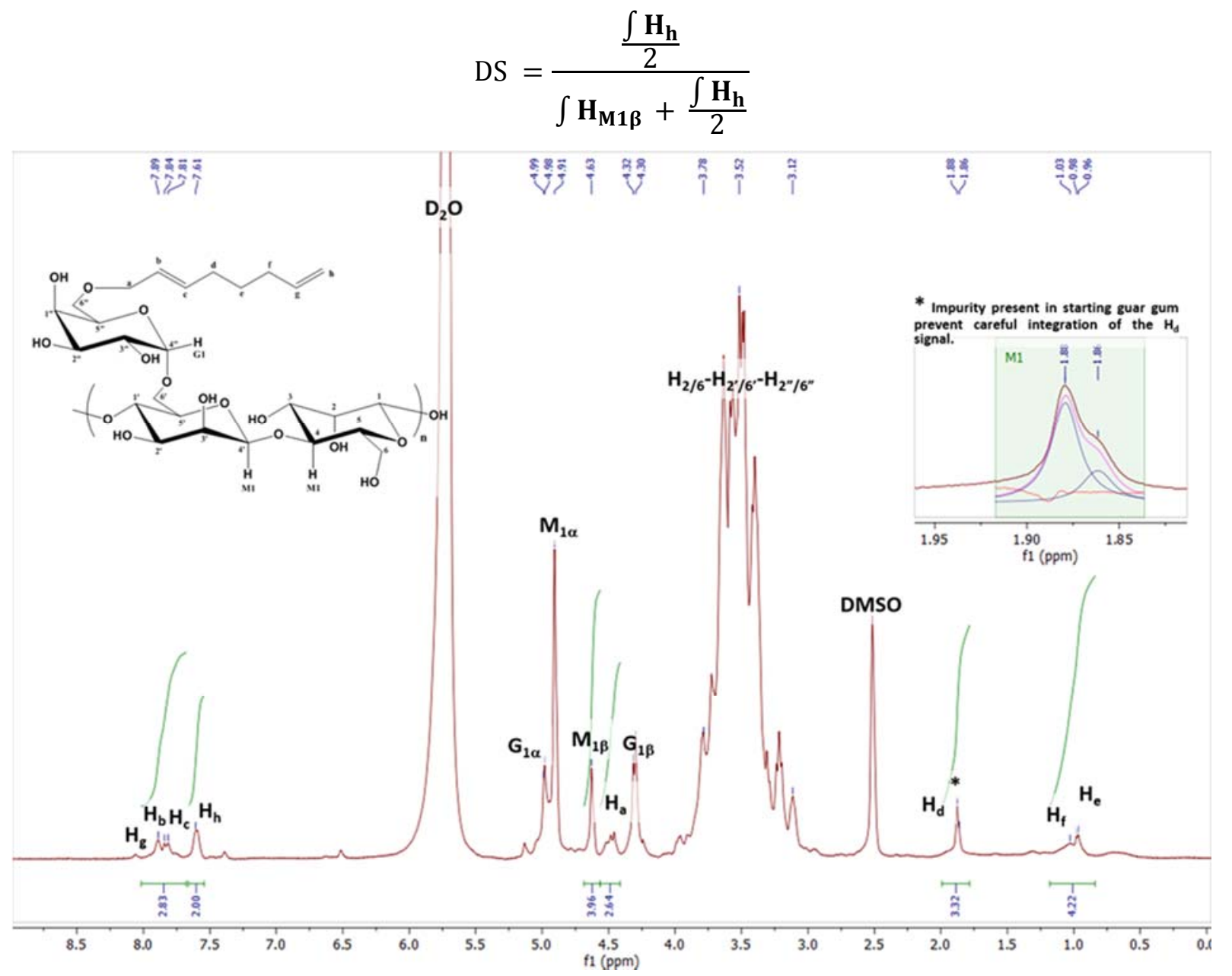

Fig. 7. ${ }^{1} \mathrm{H}$ NMR spectrum of guar hemicellulose after reaction, DS $=0.20$ (see Figure S13 in Supplementary information for ${ }^{13} \mathrm{C}$ spectrum).

\subsubsection{Influence of reaction conditions on the substitution degree of guar hemicellulose}

This section describes the most significant effects of reaction conditions on the substitution degree. Here also, and for comparison, conditions inspired from previous starch telomerization were initially applied.[9, 10] They included the presence of $\operatorname{Pd}(\mathrm{OAc})_{2}$ as $\mathrm{Pd}$ precursor, the use of basic reaction medium, and substoichoimetry of butadiene. As for chitosan we first investigated the nature of the reaction medium in the initial conditions described in Fig. 8. Note that in water/iso-propanol guar hemicellulose was a gel like solid. As for chitosan, no additive was necessary to maintain the initial aspect of this polysaccharide. Here also the presence of iso-propanol was detrimental (Fig. 8a). In addition, basic conditions were necessary to have a significant reactivity of hemicellulose (Fig. 8b). Similarly to the case of starch a substoichiometry of $\mathrm{NaOH}$ was sufficient since no DS increase was observed by increasing the $\mathrm{NaOH}$ concentration. At higher $\mathrm{NaOH}$ amounts the hydroxide groups may coordinate to the palladium limiting its activity, indicating at this stage a close reactivity between guar hemicellulose and starch. Nevertheless one can note already that in the absence of base a reactivity is nevertheless possible using $\mathrm{Pd}(\mathrm{OAc})_{2}$ as precursor (see below for discussion). The catalytic system 
giving the highest $D S$ after these first experiments was composed of $\mathrm{Pd}(\mathrm{OAc})_{2}$ with three equivalents of TPPTS in the conditions described in Fig. 8a. From this first series of experiments a DS in the range 0.09-0.30 can be obtained.
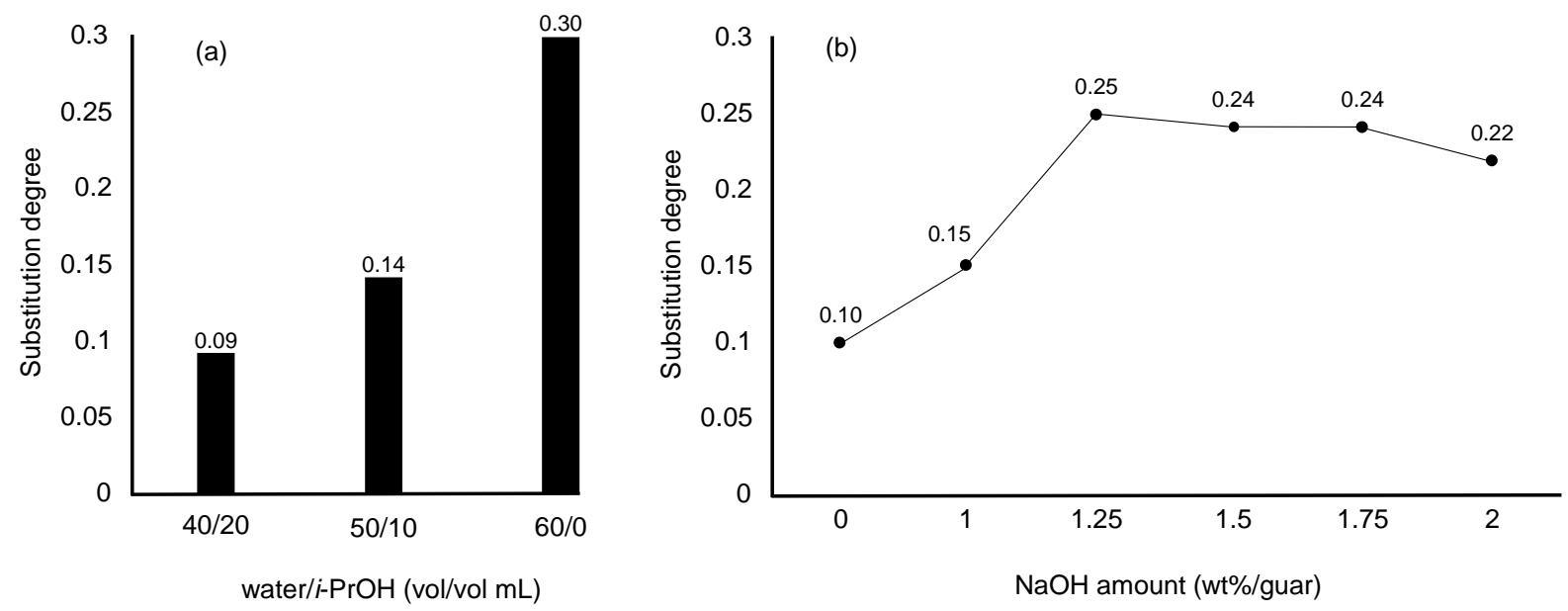

Fig. 8. Influence of solvent system for guar telomerization. (a) Guar $1 \mathrm{~g}\left(6.2 \mathrm{mmol}, 0.1 \mathrm{~mol}^{-1}, 18.6 \mathrm{mmol}\right.$ of $\left.\mathrm{OH}\right)$, $\mathrm{NaOH} 12.5 \mathrm{mg}$ (0.31 mmol, $\left.0.005 \mathrm{~mol} . \mathrm{L}^{-1}, 1.7 \mathrm{~mol} \% / \mathrm{OH}, 1.25 \mathrm{wt} \% / g u a r\right)$, butadiene $1.25 \mathrm{~mL}$ (14.1 mmol, 0.8 equiv./OH), Pd(OAc) $6.75 \mathrm{mg}$ (Pd: $0.031 \mathrm{mmol}, 516 \mu \mathrm{mol} . \mathrm{L}^{-1}, 0.5 \mathrm{~mol} \% /$ guar), TPPTS $52.8 \mathrm{mg}$ (0.093 mmol, 1550 $\mu \mathrm{mol} . \mathrm{L}^{-1}, 3$ equiv./Pd), solvent $60 \mathrm{~mL}, 40^{\circ} \mathrm{C}, 20 \mathrm{~h}$. (b) See (a) except NaOH 0-20 mg (0-0.5 mmol, 0-0.008 mol. $\mathrm{L}^{-1}$, 0-2.7 mol\%/OH, 0-2 wt\%/guar), water $60 \mathrm{~mL}, 6 \mathrm{~h}$.

Compared to chitosan, the telomerization of guar hemicellulose was more dependent on the temperature and $40{ }^{\circ} \mathrm{C}$ was sufficient to get DS in the same range as for chitosan (Fig. 9a). While for chitosan increasing the temperature up to $90{ }^{\circ} \mathrm{C}$ had no real influence, here a dramatic DS decrease was observed, even after $6 \mathrm{~h}$ of reaction. It is possible that at this temperature the basic conditions induced uncontrolled modifications of the reactant preventing reaction with butadiene. Moreover the concentration of the latter in the liquid phase also depends on temperature. Additional investigations would probably have had to be performed however not essential for the present study. At $40^{\circ} \mathrm{C}$, the DS can be increased after longer reaction time but not so significantly (Fig. 9b) and 0.30 was the maximum DS attainable in these conditions. Next studies were performed at $40^{\circ} \mathrm{C}$ for $6 \mathrm{~h}$. 

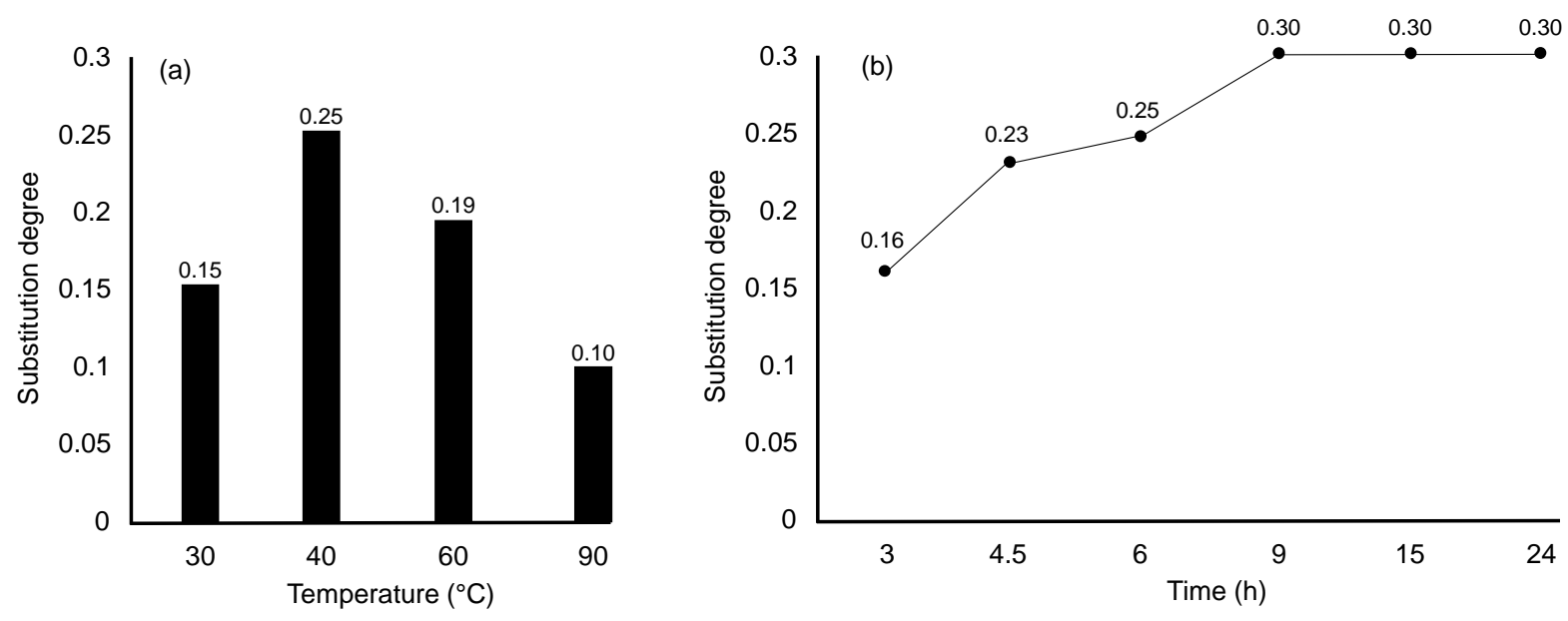

Fig. 9. Influence of time and temperature for guar telomerization. (a) Guar $1 \mathrm{~g}\left(6.2 \mathrm{mmol}, 0.1 \mathrm{~mol} . \mathrm{L}^{-1}, 18.6 \mathrm{mmol}\right.$ of $\mathrm{OH}$ ), $\mathrm{NaOH} 12.5 \mathrm{mg}$ (0.31 mmol, $0.005 \mathrm{~mol} . \mathrm{L}^{-1}, 1.7 \mathrm{~mol} \% / \mathrm{OH}, 1.25 \mathrm{wt} \% /$ guar), butadiene $1.25 \mathrm{~mL}$ (14.1 mmol, 0.8 equiv./OH), $\mathrm{Pd}(\mathrm{OAc})_{2} 6.75 \mathrm{mg}$ (Pd: $\left.0.031 \mathrm{mmol}, 516 \mu \mathrm{mol} . \mathrm{L}^{-1}, 0.5 \mathrm{~mol} \% / \mathrm{guar}\right)$, TPPTS $52.8 \mathrm{mg}$ (0.093 mmol, $1550 \mu \mathrm{mol} . \mathrm{L}^{-1}, 3$ equiv./Pd), water $60 \mathrm{~mL}, 30-90^{\circ} \mathrm{C}, 6 \mathrm{~h}$. (b) See (a) except, $40^{\circ} \mathrm{C}, 3-24 \mathrm{~h}$.

Importantly these results were obtained in substoichiometry of butadiene and in the absence of CTAB, close to the conditions reported for starch telomerization. Surprisingly increasing the amount of butadiene up to being in excess (2.5 equiv./OH) did not systematically increase the DS (Fig. 10). As in the case of chitosan a condensed butadiene liquid phase certainly formed hampering after a certain limit guar hemicellulose telomerization to take place (and the catalyst may form preferentially sideproducts) and butadiene efficiency for product formation decreased with the introduced amount. Note that this limit was much lower than for chitosan. Some reactions were performed in the presence of CTAB to try to enhance the reactivity (not presented here), but no definitive trend could be drawn from these experiments. Indeed it seemed that CTAB had a significant effect only for the highest butadiene amounts through the formation of micelles. Here it seems difficult to rationalize the observed results. As possible explanation, the different $-\mathrm{OH}$ groups of guar hemicellulose do not present similar interactions with the surrounding reaction system (primary vs. secondary alcohols, $\mathrm{H}$ bonded interactions, accessibility...), implying different intrinsic reactivity. 


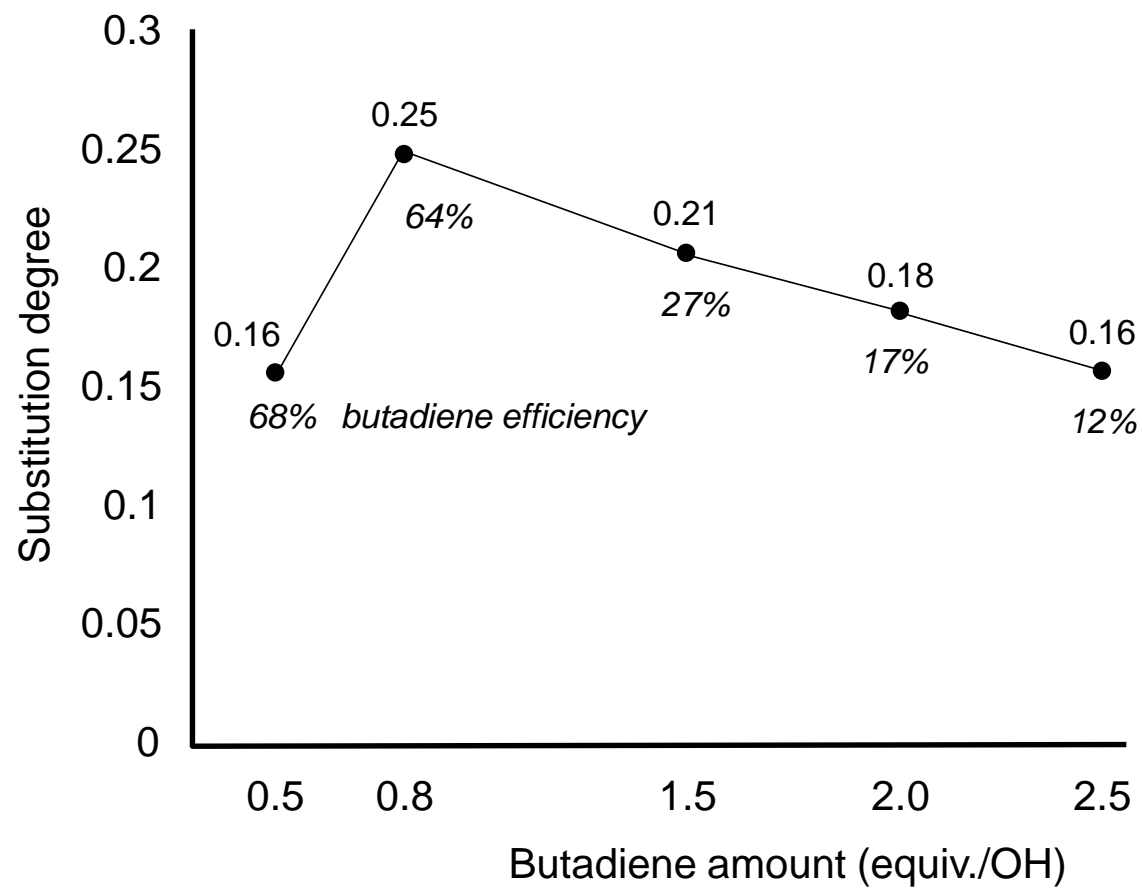

Fig. 10. Influence of butadiene amount for guar telomerization. Guar $1 \mathrm{~g}\left(6.2 \mathrm{mmol}, 0.1 \mathrm{~mol} . \mathrm{L}^{-1}, 18.6 \mathrm{mmol}\right.$ of $\mathrm{OH}$ ), $\mathrm{NaOH} 12.5 \mathrm{mg}$ (0.31 mmol, $0.005 \mathrm{~mol} . \mathrm{L}^{-1}, 1.7 \mathrm{~mol} \% / \mathrm{OH}, 1.25 \mathrm{wt} \% /$ guar), butadiene 0.78-4 mL (8.8-44 mmol, 0.5-2.5 equiv./OH), $\mathrm{Pd}(\mathrm{OAc})_{2} 6.75 \mathrm{mg}$ (Pd: $0.031 \mathrm{mmol}, 516 \mu \mathrm{mol} . \mathrm{L}^{-1}, 0.5 \mathrm{~mol} \% /$ guar), TPPTS $52.8 \mathrm{mg}$ (0.093 $\mathrm{mmol}, 1550 \mu \mathrm{mol} . \mathrm{L}^{-1}, 3$ equiv./Pd), solvent $60 \mathrm{~mL}, 40^{\circ} \mathrm{C}, 6$ hours.

The nature of Pd precursor and of the base had a significant influence (Fig. 11). In contrast to the case of chitosan, $[\mathrm{Pd}(\mathrm{allyl}) \mathrm{Cl}]_{2}$ was less efficient and $\mathrm{Pd}(\mathrm{OAc})_{2}$ gave higher DS. Interestingly, $\mathrm{Pd}(\mathrm{acac})_{2}$ was much less efficient in these conditions and can be used to obtain lower DS. This is in contrast to reported observations for telomerization of simple sugars in water for which $\mathrm{Pd}(\mathrm{acac})_{2}$ (associated to TPPTS) is one of the most efficient precursor.[37] Probably the influence of other factors such as the base is of importance for the formation and stabilization of the active catalytic species. As seen above in the absence of base a lower DS was obtained (0.10, see Fig. 8) using $\operatorname{Pd}(\mathrm{OAc})_{2}$. However increasing the amount of $\mathrm{Pd}(\mathrm{OAc})_{2}$ led to a DS of 0.3 even in the absence of base. It seems therefore that the anion of the Pd precursor had an influence in the transformation playing the role of base. This was confirmed using $\mathrm{NaOAc}$ in place of $\mathrm{NaOH}$ and the same level of DS was obtained. While for chitosan the concentration of TPPTS had a relatively low effect on the reaction, in the case of hemicellulose it significantly influences the DS and clearly 2 to 3 equivalents of ligand have to be used to observe the highest substitution (Fig. 11b). Here also it appears difficult to explain the observed difference between chitosan and guar hemicellulose reactivity in terms of catalyst nature. Probably the presence of $\mathrm{NaOH}$ has an influence on the catalyst stability, both regarding the Pd precursor and the ligand. 

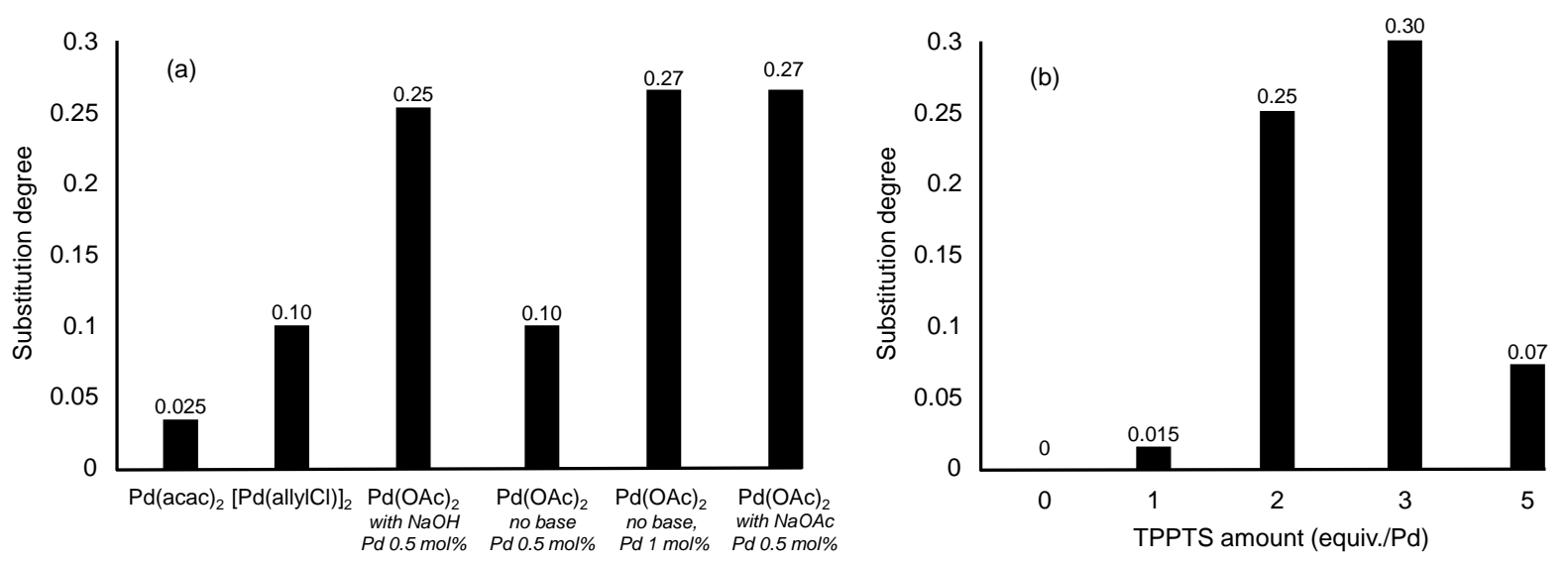

Fig. 11. Influence of catalytic system for guar telomerization. (a) Guar $1 \mathrm{~g}$ (6.2 mmol, $0.1 \mathrm{~mol} . \mathrm{L}^{-1}, 18.6 \mathrm{mmol}$ of $\mathrm{OH}$ ), $\mathrm{NaOH} 12.5 \mathrm{mg}$ (0.31 mmol, $0.005 \mathrm{~mol} . \mathrm{L}^{-1}, 1.7 \mathrm{~mol} \% / \mathrm{OH}, 1.25 \mathrm{wt} \% /$ guar), butadiene $1.25 \mathrm{~mL}$ (14.3 mmol,

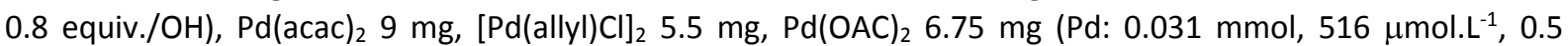
mol\%/guar), TPPTS $52.8 \mathrm{mg}\left(0.093 \mathrm{mmol}, 1550 \mu \mathrm{mol} . \mathrm{L}^{-1}, 3\right.$ equiv./Pd), water $60 \mathrm{~mL}, 40{ }^{\circ} \mathrm{C}, 6$ hours. (b) See (a) except Pd(OAc) $6.75 \mathrm{mg}$ (Pd: $0.031 \mathrm{mmol}, 516 \mu \mathrm{mol} . \mathrm{L}^{-1}, 0.5 \mathrm{~mol} \% /$ guar), TPPTS 0-88 mg (0-0.155 mmol, 0-2583 $\mu \mathrm{mol} . \mathrm{L}^{-1}, 0-5$ equiv./Pd), 20 hours.

As a conclusion on this first study on the telomerization of guar hemicellulose with butadiene, even combining several parameters it was possible to reach a DS no more than 0.3 corresponding to the average substitution of about 1 -OH group per sugar unit. A DS of 0.1-0.3 can globally be obtained over different conditions.

\section{Physico-chemical properties}

The thermal stability of the biopolymers after modification was assessed using thermogravimetry analysis. Fig. S16 in Supporting information indicates that there was no significant changes after telomerization and both biopolymers kept intrinsic thermal stability up to ca. $250^{\circ} \mathrm{C}$.

More importantly, one target of the modification by telomerization was to modify the hydrophilicity/hydrophobicity of the biopolymers by the presence of the 8 carbon chain. Initial assessment has been carried out by qualitatively observation of the surface of the materials after deposition of a water drop. In both cases Fig. 12 shows that the water droplet was totally adsorbed by initial chitosan and hemicellulose. The same observation was made with biopolymers modified with very low DS (e.g. < 0.1), indicating no significant hydrophobicity change. This comes in contrast to the case of starch for which one modification was clearly already perceptible at this level of substitution.[9] For higher DS, in 0.20 range, top of the droplet can be seen at the surface indicating that only partial water adsorption occurred due to introduced hydrophobic character at the biopolymer surface. For the highest DS (0.60 and 0.30, respectively) the difference was more perceptible and pictures show clearly the presence of the droplet at the surface. Average contact angles of $105^{\circ}$ and $121^{\circ}$ indicate a 
very low wetting ability of the modified biopolymers at this extent of substitution, resulting from hydrophobisation of the surface.

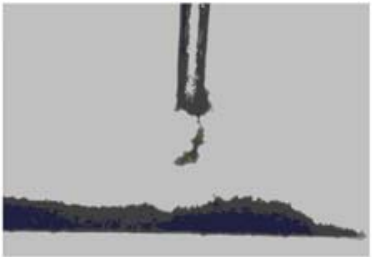

initial chitosan

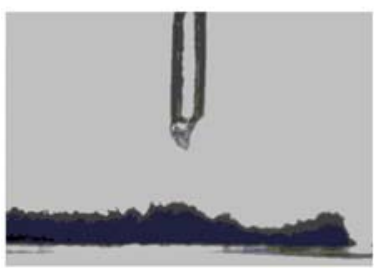

initial guar hemicellulose

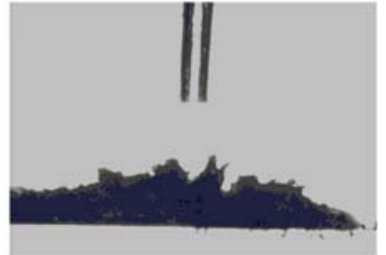

DS 0.03

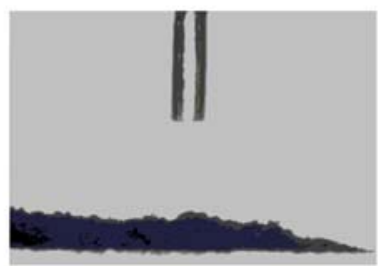

DS 0.07

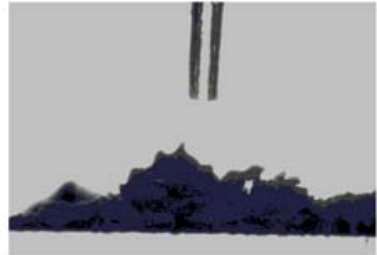

DS 0.25

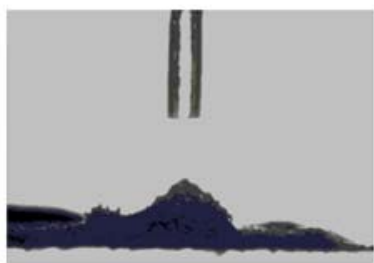

DS 0.21

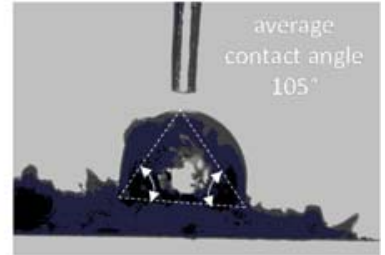

DS 0.60

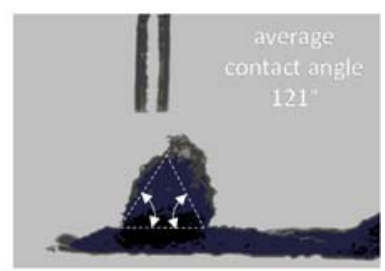

DS 0.30

Fig. 12. Pictures of chitosan (top) and guar hemicellulose (bottom) surface after deposition of a water droplet.

\section{Conclusion}

This paper describes for the first time the catalyzed telomerization of two important biopolymers, chitosan and a guar (galactomannan) hemicellulose. These reactions with butadiene gave new biosourced materials following a straightforward procedure. These polymers were deeply characterized using ${ }^{1} \mathrm{H}$ and ${ }^{13} \mathrm{C}$ NMR spectroscopy allowing an accurate molecular description of the products. Importantly, both reactions were possible in water as solvent in the presence of a low amount of catalyst. The water soluble catalytic system consisted of a Pd precursor with TPPTS as ligand. The objective was not to study the combined impact of all the factors that may govern the transformation leading to high substitution degree (DS), but to show the possibility of adjusting the DS by defining precisely some reaction conditions. Some differences were observed between chitosan and guar hemicellulose and the most influent parameters were not systematically the same, as an example, efficient chitosan telomerization necessitated the presence of CTAB surfactant. By combining the effect of some parameters it was possible to tune the modification with DS in the 0.03-0.60 range for chitosan and 0.025-0.3 range for guar hemicellulose. Comparison with previously reported starch telomerization has also been described when pertinent. Due to its homogenous nature, catalyst recovery appears difficult and was not assessed during this study and this may limit the sustainability of the procedure. However, and very importantly, this catalytic procedure formed new biopolymers and the most substituted presented a superior hydrophobic character that can be of interest for specific applications as described in the Introduction. 


\section{Acknowledgments}

W. Z. thanks the Lebanese University for a PhD fellowship. The authors warmly acknowledge Dr E. Puzenat and F. Dappoze (IRCELYON) for water dropping experiments, C. Lorentz (IRCELYON) for solidsate NMR experiments, and C. Duchamp (Centre Commun de Spectrométrie de Masse de l'Université Lyon 1) for MS analysis.

\section{References}

[1] T.A. Faßbach, A.J. Vorholt, W. Leitner, The telomerization of 1,3-dienes - A reaction gows up, ChemCatChem 11 (2019) 1153-1166.

[2] N. Herrmann, D. Vogelsang, A. Behr, T. Seidensticker, Homogeneously catalyzed 1,3-diene functionalization - A success story from laboratory to miniplant scale, ChemCatChem 10 (2018) 53425365.

[3] A. Behr, M. Becker, T. Beckmann, L. Johnen, J. Leschinski, S. Reyer, Telomerization: Advances and applications of a versatile reaction, Angew. Chem. Int. Ed. 48 (2009) 3598-3614.

[4] I. Pantelic, B. Cuckovic, Alkyl polyglucosides: an emerging class of sugar surfactants, in Alkyl polyglucosides, from natural-origin surfactants to prospective delivery systems, Woodhead Publishing Series in Biomedecine, Editor Ivana Pantelic, 2014, p. 1-19.

[5] S. Bouquillon, J. Muzart, C. Pinel, F. Rataboul, Palladium-catalyzed telomerization of butadiene with polyols: from mono to polysaccharides, Top. Curr. Chem. 295 (2010) 93-119.

[6] C. Hadad, C. Damez, S. Bouquillon, B. Estrine, F. Hénin, J. Muzart, I. Pezron, L. Komunjer, Neutral pentosides surfactants issued from the butadiene telomerization with pentoses: preparation and amphiphilic properties, Carbohydr. Res. 341 (2006) 1938-1944.

[7] C. Dumont, R.M. Gauvin, F. Belva, M. Sauthier, Palladium-catalyzed functionalization of Kraft lignin: Ether linkages through the telomerization reaction, ChemSusChem 11 (2018) 1649-1655.

[8] P.J.C. Hausoul, S.D. Tefera, J. Blekxtoon, P.C.A. Bruijnincx, R.J.M. Klein Gebbink, B.M. Weckhuysen, $\mathrm{Pd} / \mathrm{TOMPP}$-catalysed telomerisation of 1,3-butadiene with lignin-type phenols and thermal Claisen rearrangement of linear telomers, Catal. Sci. Technol. 3 (2013) 1215-1223.

[9] J. Mesnager, C. Quettier, A. Lambin, F. Rataboul, A. Perrard, C. Pinel, Telomerization of butadiene with starch in water: role of the surfactants, Green Chem. 12 (2010) 475-482.

[10] J. Mesnager, C. Quettier, A. Lambin, F. Rataboul, C. Pinel, Telomerization of butadiene with starch under mild conditions, ChemSusChem 2 (2009) 1125-1129.

[11] N. Masina, Y.E. Choonara, P. Kumar, L.C. du Toit, M. Govender, S. Indermun, V. Pillay, A review of the chemical modification techniques of starch, Carbohydr. Polym. 157 (2017) 1226-1236.

[12] D. Klemm, B. Heublein, H.-P. Fink, A. Bohn, Cellulose: Fascinating biopolymer and sustainable raw material, Angew. Chem. Int. Ed. 44 (2005) 3358-3393.

[13] P. Mäki-Arvela, T. Salmi, B. Holmbom, S. Willför, D.Y. Murzin, Synthesis of sugars by hydrolysis of hemicelluloses- A review, Chem. Rev. 111 (2011) 5638-5666.

[14] K. Petzold-Welcke, K. Schwikal, S. Daus, T. Heinze, Xylan derivatives and their application potential - Mini-review of own results, Carbohydr. Polym. 100 (2014) 80-88. 
[15] H.J. Prado, M.C. Matulewicz, Cationization of polysaccharides: A path to greener derivatives with many industrial applications, Eur. Polym. J. 52 (2014) 53-75.

[16] P. Peng, D. She, Isolation, structural characterization, and potential applications of hemicelluloses from bamboo: A review, Carbohydr. Polym. 112 (2014) 701-720.

[17] F.-Z. Belmokaddem, C. Pinel, P. Huber, M. Petit-Conil, D. Da Silva Perez, Green synthesis of xylan hemicellulose esters, Carbohydr. Res. 346 (2011) 2896-2904.

[18] V. Bigand, C. Pinel, D. Da Silva Perez, F. Rataboul, P. Huber, M. Petit-Conil, Cationization of galactomannan and xylan hemicelluloses, Carbohydr. Polym. 85 (2011) 138-148.

[19] V. Bigand, C. Pinel, D. Da Silva Perez, F. Rataboul, M. Petit-Conil, P. Huber, Influence of liquid or solid phase preparation of cationic hemicelluloses on physical properties of paper, BioResources 8 (2013) 2118-2134.

[20] S.K. Shukla, A.K. Mishra, O.A. Arotiba, B.B. Mamba, Chitosan-based nanomaterials: A state-of-theart review, Int. J. Biol. Macromol. 59 (2013) 46-58.

[21] A. El Kadib, Chitosan as a sustainable organocatalyst: A concise overview, ChemSusChem 8 (2015) 217-244.

[22] V. Balan, L. Verestiuc, Strategies to improve chitosan hemocompatibility: A review, Eur. Polym. J. 53 (2014) 171-188.

[23] F. Croisier, C. Jérôme, Chitosan-based biomaterials for tissue engineering, Eur. Polym. J. 49 (2013) 780-792.

[24] V.K. Thakur, M.K. Thakur, Recent advances in graft copolymerization and applications of chitosan: A review, ACS Sustainable Chem. Eng. 2 (2014) 2637-2652.

[25] H. Sashiwa, S.-i. Aiba, Chemically modified chitin and chitosan as biomaterials, Progr. Polym. Sci. 29 (2004) 887-908.

[26] W. Zahreddine, Q. Lelong, I. Karame, A. Kanj, C. Pinel, L. Djakovitch, F. Rataboul, Synthesis of terpene derivatives of ethanolamine using telomerization reaction, Tetrahedron Lett. 57 (2016) 452457.

[27] T.A. Faßbach, S. Püschel, A. Behr, S. Romanski, D. Leinweber, A.J. Vorholt, Towards a process for the telomerization of butadiene with N-methylglucamine, Chem. Eng. Sci. 181 (2018) 122-131.

[28] T.A. Faßbach, F.O. Sommer, A. Behr, S. Romanski, D. Leinweber, A.J. Vorholt, Non-ionic surfactants from renewables - Amphiphilic ligands in biphasic reactions, Catal. Sci. Technol. 7 (2017) 1650-1653.

[29] P.K. Dutta, J. Dutta, V.S. Tripathi, Chitin and chitosan: Chemistry, properties and applications, J. Sci. Ind. Res. 63 (2004) 20-31.

[30] L. Heux, J. Brugnerotto, J. Desbrières, M.F. Versali, M. Rinaudo, Solid state NMR for determination of degree of acetylation of chitin and chitosan, Biomacromolecules 1 (2000) 746-751.

[31] F.S. Pereira, H.D.L. Nascimento, A. Magalhães, M.G. Peter, G.A. Bataglion, M.N. Eberlin, E.R.P. González, ESI(+)-MS and GC-MS study of the hydrolysis of N-azobenzyl derivatives of chitosan, Molecules 19 (2014) 17604-17618.

[32] A.B. Sorokin, F. Quignard, R. Valentin, S. Mangematin, Chitosan supported phthalocyanine complexes: Bifunctional catalysts with basic and oxidation active sites, Appl. Catal. A 309 (2006) 162168.

[33] R. Palkovits, A.N. Parvulescu, P.J.C. Hausoul, C.A. Kruithof, R.J.M. Klein Gebbink, B.M. Weckhuysen, Telomerization of 1,3-butadiene with various alcohols by Pd/TOMPP catalysts: New opportunities for catalytic biomass valorization, Green Chem. 11 (2009) 1155-1160.

[34] T.A. Faßbach, R. Kirchmann, A. Behr, S. Romanski, D. Leinweber, A.J. Vorholt, Telomerization of 1,3-butadiene with highly substituted alcohols using Pd/NHC-catalysts - Structure-reactivityrelationship of the O-nucleophile, J. Mol. Catal. A 423 (2016) 526-532.

[35] T. Iwasawa, M. Tokunaga, Y. Obora, Y. Tsuji, Homogeneous palladium catalyst suppressing Pd black formation in air oxidation of alcohols, J. Am. Chem. Soc. 126 (2004) 6554-6555.

[36] J. Mesnager, E. Kuntz, C. Pinel, Isolated-palladium complexes for catalyzed telomerization of butadiene with methanol in the presence of water, J. Organomet. Chem. 694 (2009) 2513-2518.

[37] B. Estrine, S. Bouquillon, F. Hénin, J. Muzart, Telomerization of butadiene with pentoses in water: selective etherifications, Green Chem. 7 (2005) 219-223. 
